\title{
Comparison of the Effect of Lavender and Bitter Orange on Depression in Menopausal Women: A Triple-Blind Randomized Controlled Trial
}

\author{
Mahin Kamalifard ${ }^{1}$, Azizeh Farshbaf Khalili ${ }^{2}$, Mahsa Namadian ${ }^{1 *}$, Sepideh Herizchi ${ }^{3}$, Yunes Ranjbar ${ }^{4}$
}

\begin{abstract}
Objectives: Menopause is an inevitable milestone and an important stage in every woman's life. This study aimed to compare the effects of lavender and bitter orange on depression in menopausal women.

Materials and Methods: This triple-blind randomized controlled clinical trial was conducted on 156 menopausal women in Urmia, Iran in 2015. Eligible women were allocated into 2 intervention groups and one control group with a ratio of 1:1:1 through the randomized block design. Intervention groups received $500 \mathrm{mg}$ capsules containing only bitter orange or lavender flower's powder and control group received $500 \mathrm{mg}$ starch capsules, all groups used capsules twice daily after breakfast and dinner for 8 weeks. Capsules were in the same appearance. Beck Depression Inventory was completed by the participants before and 8-week after the commencement intervention. The analysis was performed based on intention to treat approach.

Results: The one-way analysis of variance (ANOVA) analysis showed no significant difference in mean depression score in the three groups before the intervention $(P=0.262)$; however, the general linear model test adjusted for base line and confounding factors such as menopausal age and women age showed significant differences between the groups in the mean depression score after 8 weeks of treatment $(P<0.001)$. Bitter orange significantly reduced the mean depression score compared with the control group (adjusted mean difference [AMD], $-2.88 ; 95 \% \mathrm{CI},-4.26$ to -1.51$)$. Lavender significantly reduced the mean depression scores compared with the control group as well (AMD, $-3.01 ; 95 \% \mathrm{CI},-4.40$ to -1.63 ). There was no significant between lavender and bitter orange groups after intervention $(P=0.850)$.

Conclusion: Considering the positive effect of bitter orange and lavender in reducing depression in menopausal women, they can be used as a complementary medicine in depressed patients.

Keywords: Depression, Menopause, Lavender, Citrus aurantium, Bitter orange
\end{abstract}

\section{Introduction}

Menopause is an inevitable milestone and an important stage in every woman's life (1) and a physiological event that occurs due to lack of ovarian activity and permanent cessation of menstruation and it is when 12 months have passed from the last menstrual period (2). Since one third of women's life is spent after menopause, there should be conditions for postmenopausal women to experience a life with high quality without pain, illness, and disability. Menopause is a natural and important stage of women's life that occurs between the ages of 45 and 55 and the average age for menopause is $50(3,4)$. In developed countries, the average age at menopause is about 51 years, whereas in countries like India (5), Philippines, Pakistan and Thailand, it is reported to be $45-50$ years (6). The average age of menopause in Iran was reported as 48.2 in 2011 (7).

The population of postmenopausal women is estimated to increase from 742150000 in 2010 to 1.2 billion until 2030, and the most of this enhancement will occur in developing countries (8). Decreased estrogen levels are as- sociated with a wide range of menopausal symptoms, the most common vasomotor symptoms include hot flashes and night sweats (9). Symptoms such as irritability, anger and depression also aggravate at menopause (10).

In a study in 2013 in Pakistan, prevalence of depression in postmenopausal women was reported as $39.4 \%$ (1) and it was reported as $34.7 \%$ in postmenopausal women in Dezful, Iran (11). Reduced estrogen levels in menopause indicates that the cause of depression is related to female hormones (12). Depression can negatively affect social functioning and may cause loss of interest in enjoyable activities, sleep problems, loss of appetite or increased appetite, feeling of sadness, tiredness, low energy and even lead to suicide attempts (13).

Although medical treatment including hormone therapy and relaxation therapy are considered the first-line of treatment for depression, many women are not eligible to use them (14). Several potential side effects have been associated with hormone therapy including thromboembolism, gallstones, cerebral stroke, breast and endometrial 
cancer (15). The use of tricyclic antidepressants and selective serotonin reuptake inhibitor to treat depression also has side effects such as anticholinergic effects, orthostatic hypotension and arrhythmia (16).

Lavender with the scientific name Lavandula angustifolia contains linalool, linalyl acetate, ocimene, camphor, caryophyllene oxide, tannins, coumarin, flavonoid and phytosterol (17) which have antidepressant (18), sedative, local anesthetic, dose-dependent anti-seizure (19), hypnotic (18), antioxidant and anti-anxiety (20) effects. Its linalool that affects the noradrenaline and dopamine levels and explains its antidepressant effects (21). This plant has been used in different studies without any certain reported side effects $(22,23)$, only in some cases, nausea and vomiting (24) and skin dermatitis (25) had been observed in the case of topical use. Lavender has been confirmed by the World Health Organization (WHO) (26).

Bitter orange with the scientific name of Citrus aurantium belongs to the Rutaceae family and contains limonene, linalool, linalyl acetate, carotene, coumarin, flavonoid, pectin and p-synephrine (27). It has sedative (28), weight loss (28), hypnotic (29) and anti-anxiety (27) effects. Flavonoid and p-synephrine found in bitter orange has antidepressant effects (29).

Bitter orange with a dose of $975 \mathrm{mg}$ (54 mg p-synephrine $6 \%$ ) for 6 weeks in order to lose weight had not caused any particular side effect (30), while dermal use led to sensitivity to light (29). Bitter orange has been confirmed by US Food and Drug Administration (FDA) (27).

According to WHO report, in most countries because of herbal medicine's effectiveness, low risk and accessibility, there is an increasing trend toward consumption of complementary medicine for therapeutic reasons. In third world countries, majority of people utilize herbal medicine for treating their disease due to the lower cost of herbal plants (31).

No study has been conducted to compare the effect of these 2 medicinal planes on menopausal depression. Few studies have been conducted on the effect of bitter orange on depression (32), while study of the effects of lavender on depression has yielded contradictory results $(24,33,34)$ and most studies have had an aromatherapy approach $(32,33,35)$. Therefore, given the side effects of antidepressants drugs, popularity of complementary medicine and since one of the important responsibilities of midwives in primary care is the menopausal care, this study aimed to compare the effects of lavender and bitter orange on depression in menopausal women.

\section{Materials and Methods}

Study Design and Participants

This study was a triple-blind randomized controlled trial that was conducted on 156 menopausal women. The inclusion criteria were: The 45-60 years old women, with last menstruation of 1-6 years ago which started naturally, who get 14-28 from Beck depression score, without taking anti-depressant drugs, tobacco and alcohol, having phone number for follow-up, without history of asthma and allergy to specific plants or citrus, lack of acute gastrointestinal problems declared by herself, Urmia residents, agreeing to participate in the study.

The exclusion criteria of the study were: Having to travel or change home during intervention, prior history of depression or any other mental disorder, unpleasant occurrences such as death of a family member during last three months, encountering events that caused depression, regular weekly exercise and use of other methods of traditional medicine.

G*Power (version 3.1.2) was used to determine the sample size. Based on the information in the study by Nikfarjam et al (34) $\mathrm{m}_{1}=21.6$ (mean depression in their study), $m_{2}=18.36$ (considering at least $5 \%$ increase through our intervention), $s \mathrm{~d}_{1}=\mathrm{sd}_{2}=4.9, \alpha=0.05, \beta=0.2$, sample size was determined 47 women per group and finally regarding $10 \%$ sample loss, the final sample size was estimated as 52 participants for each group.

\section{Sampling}

Research setting included the gynecology clinics in Imam Reza and Fatemiyeh hospitals in Urmia, Iran. All menopausal women were assessed for eligibility criteria in the selected clinics through the convenience sampling method. Socio-demographic questionnaire and Beck Depression Inventory were completed by the participants. Score 28 or higher was indicative of severe depression, in which case, the subjects would be referred to the mental health service provider and excluded from randomization. Participants with a score of 14-28 in Beck Depression Inventory (mild to moderate depression) were included in the study.

Methodology, possible risks, potential benefits, and the nature of voluntary participation in the study were explained to the subjects. A checklist was also provided for the participants to record daily consumption of the capsules and possible side effects.

\section{Randomization and Intervention}

Allocation sequence was determined by computer random number table with blocks size of 3 and 6 and 1:1:1 allocation ratio. The women were randomly divided into 3 groups of bitter orange, lavender and placebo. Capsules contained only $500 \mathrm{mg}$ of bitter orange or lavender flower's powder, while placebo capsules contained $500 \mathrm{mg}$ starch. All capsules were similar in appearance and were prepared by Yashil Sahand Drug Incorporation in East Azerbaijan region, Iran. An opaque sealed envelope was given to each participant. Envelopes were numbered consecutively from 1 to 156 and prepared by non-involved person according to random sequence which contained the 120 lavender, bitter orange or placebo capsules for 8-week consumption.

The drugs were taken twice daily (after breakfast and dinner). In order to ensure about the administration of drugs, participants were followed up in weeks 2 and 6 via telephone. Participants, data collector and those assessing outcomes were blind in this research. 


\section{Data Collection}

Data was collected using a socio-demographic questionnaire and Beck Depression Inventory that were completed at baseline and 8 weeks after the commencement intervention. The socio-demographic questionnaire contained items on demographic information including: age, time passed since menopause, age at menopause, education, woman's and husband's occupation, and sufficiency of family monthly income for living expenses.

Beck Depression Inventory is one of the most suitable measures to reflect the state of depression. It includes 21 multiple choice questions on a four-point scale from 0 to 3 with a total score of 0-63 that was completed in 5-10 minutes. The menopausal women selected the choices that they had felt in the past 2 weeks. A score of 28 and higher was considered severe depression. Those with a score of 14-28 (mild to moderate depression) were enrolled in the study. This is a standard and approved questionnaire. Beck et al obtained a test retest reliability coefficient of 0.93 for the questionnaire. In a study on 125 students of Tehran University and Allameh Tabatabai University to evaluate the reliability and validity of BDI-II on Iranian population, a Cronbach alpha of 0.78 and test-retest reliability coefficient of 0.73 within 2 weeks were obtained (36).

Beck Depression Inventory was completed again by all participants 8 weeks after the commencement intervention. The day before the visit, a reminder phone call was made in order to completion of questionnaires.

\section{Statistical Analysis}

Data were analyzed using SPSS 22. Normality of the con- tinuous variables was confirmed using the one-sample Kolmogorov-Smirnov test. The chi-square, trend chisquare test and Fisher exact test were used for categorical variables and one-way analysis of variance (ANOVA) was used for continuous variables to examine homogeneity regarding socio-demographic or background characteristics. ANOVA was used to compare the mean depression score at baseline between groups. General linear model adjusted for baseline and confounding factors such as menopausal age and women age was used for after the intervention. At all stages, the significance level was set to $\alpha=0.05$ and all calculations were based on intention-to-treat analysis.

\section{Results}

The recruitment of participants and their follow-up were carried out from July 5, 2015 to November 21, 2015. All women who were available in this study were 400 people, but 244 were excluded as 190 women did not meet the eligibility criteria, and 54 were not willing to participate in the study. Finally, 156 menopausal women participated in the study. Fifty-two women were randomly assigned to each group. Four participants in the bitter orange group, 3 in the lavender group and 4 in the placebo group did not take the capsules. All 156 menopausal women completed the questionnaires at baseline and 8 weeks after the commencement intervention and were analyzed (Figure 1). There was no statistically significant difference among the 3 groups based on socio-demographic characteristics, except age at menopause $(P=0.029)$ and women age $(P=0.011)$ and the 3 groups were similar (Table 1$)$.

The mean (SD) of participants' age in lavender, bitter

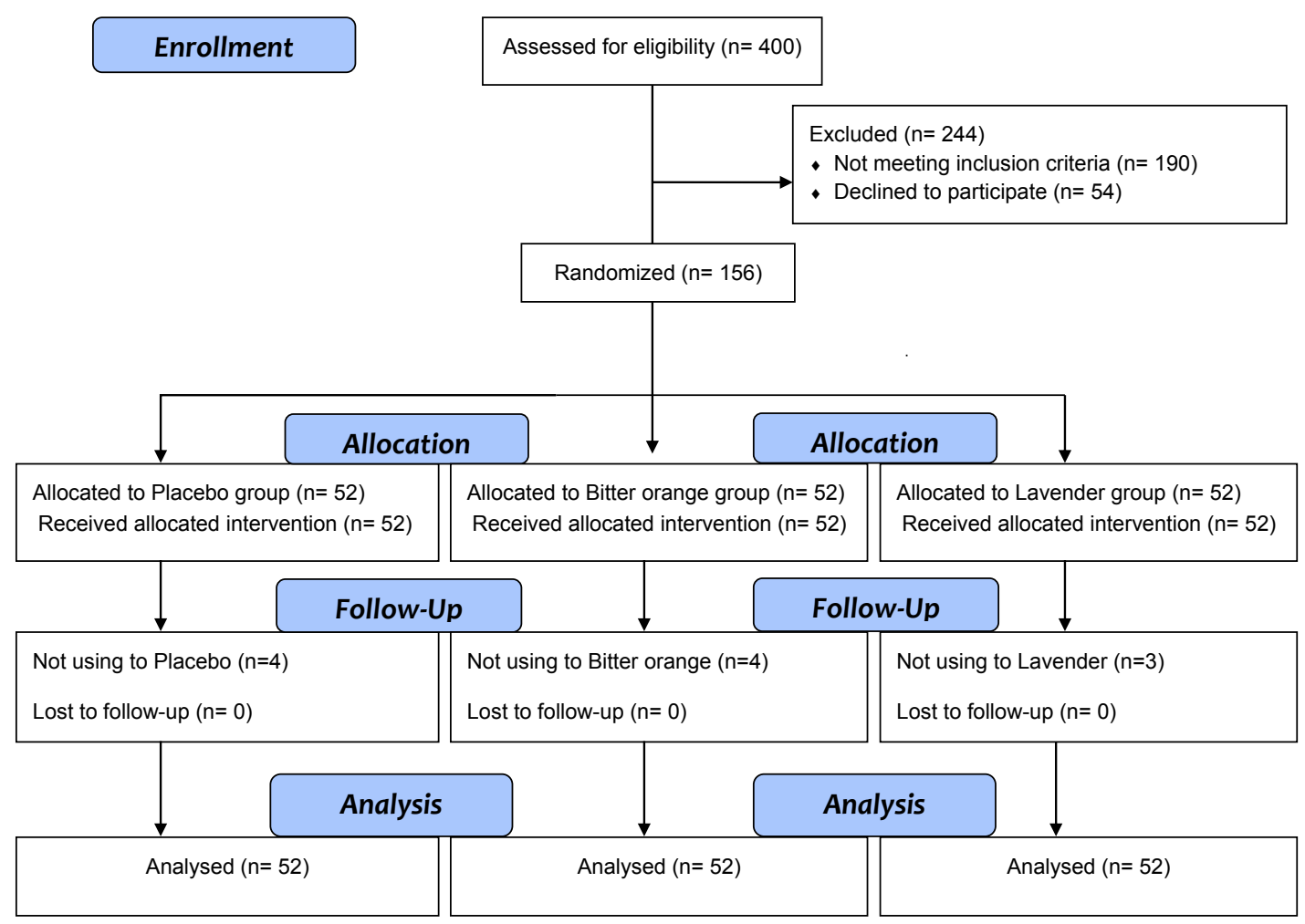

Figure 1. Flowchart of the Participants Through Each Stage of the Trial. 
orange and control groups was 54.21 (3.86), 53.65 (3.55) and 52.12 (3.49), respectively. The results of other socio-demographic characteristics of the 3 groups are presented in Table 1.

The general linear model analysis showed that difference in mean score of depression was statistically significant among groups after intervention adjusted for baseline values and confounding factors. Before the intervention, the mean (SD) depression score in the groups receiving lavender 20.82 (4.30), bitter orange 21.38 (4.33) and the control group was 20.01 (4.13) and there was no statistically significant difference between the groups $(P=0.262)$. The mean (SD) depression score was 14.07 (3.41) in the lavender group; 14.48 (4.24) in the bitter orange group; and 16.78 (4.16) in the control group 8 weeks after the intervention, showing a statistically significant difference between the groups $(P<0.001)$.

Significant differences were observed between the group receiving lavender and the control group (adjusted mean difference $[\mathrm{AMD}],-3.01 ; 95 \% \mathrm{CI},-4.40$ to -1.63 ) and between the group receiving bitter orange and the control group (AMD, -2.88 ; 95\% CI, -4.26 to -1.51 ). No statistically significant difference was found between the group receiving bitter orange and the group receiving lavender after the intervention (AMD, 0.12; 95\% CI, -1.21 to 1.47) (Table 2).

Paired $t$ test showed a significant difference in depres- sion scores after the intervention compared to baseline in the lavender (mean difference [MD], 6.75; 95\% CI, 5.507.99), bitter orange (MD, 6.90; 95\% CI, 5.91-7.89) and the control groups (MD, 3.23; 95\% CI, 2.04-4.41) (Figure 2).

In total, $83.4 \%$ of the participants in the bitter orange group, $83.7 \%$ in the lavender group, and $43.8 \%$ in the control group reported a good recovery. The group receiving bitter orange reported the highest satisfaction (79.2\%).

The frequency of side effects reported by the menopausal women in the bitter orange group was as follows: nausea (4.2\%), palpitations (4.2\%) and headache (2.1\%), in the lavender group included nausea (8.2\%), palpitations $(4.4 \%)$ and headache $(4.1 \%)$ and in the control group included nausea (10.4\%), palpitations $(2.1 \%)$ and headache (6.3\%) (Table 3$)$.

\section{Discussion}

Findings suggested the effectiveness of administration of $500 \mathrm{mg}$ bitter orange and lavender twice daily for 8 weeks in reducing the menopausal women's depression. Our results are consistent with those reported by the double-blind study conducted by Akhondzadeh, which aimed at comparing lavender tincture and imipramine in the treatment of mild to moderate depression on 48 outpatients aged 18 to 45 years visiting Roozbeh outpatient clinic in Tehran and showed that the combination of imipramine and lavender tincture was more effective than

Table 1. Demographic Characteristics of the Participants in Control and Intervention Groups

\begin{tabular}{|c|c|c|c|c|}
\hline Characteristics & $\begin{array}{c}\text { Placebo }(n=52) \\
\text { No. }(\%)\end{array}$ & $\begin{array}{c}\text { Lavender }(n=52) \\
\text { No. }(\%)\end{array}$ & $\begin{array}{c}\text { Bitter Orange }(n=52) \\
\text { No. }(\%)\end{array}$ & $P$ Value \\
\hline Age $(y)^{\text {a }}$ & $52.12(3.49)$ & $54.21(3.86)$ & $53.65(3.55)$ & $0.011^{b}$ \\
\hline Menopausal Age a & $48.00(6.72)$ & $50.35(3.37)$ & $49.90(3.23)$ & $0.029^{b}$ \\
\hline Time passed from menopause ${ }^{a}$ & $3.25(1.37)$ & $3.87(1.40)$ & $3.75(1.46)$ & $0.065^{b}$ \\
\hline Female education & & & & $0.134^{c}$ \\
\hline Primary & $13(25)$ & $20(38.5)$ & $31(59.6)$ & \\
\hline Secondary & $10(19.2)$ & $13(25)$ & $7(13.5)$ & \\
\hline High school & $7(13.5)$ & $5(9.6)$ & $4(7.7)$ & \\
\hline Diploma and University & $22(42.3)$ & $14(26.9)$ & $10(19.2)$ & \\
\hline Number of children & & & & $0.104^{d}$ \\
\hline $0-2$ & $26(50)$ & $19(36.5)$ & $15(28.8)$ & \\
\hline $3-4$ & $23(44.2)$ & $23(44.2)$ & $28(53.8)$ & \\
\hline 5 and more & $3(5.8)$ & $10(19.2)$ & $9(17.3)$ & \\
\hline Use hormone medicine & & & & $0.535^{\mathrm{e}}$ \\
\hline Yes & $1(1.9)$ & $3(5.8)$ & $4(7.7)$ & \\
\hline No & $51(98.1)$ & $49(94.2)$ & $48(92.3)$ & \\
\hline Job & & & & $0.161^{e}$ \\
\hline Housewife & $44(84.6)$ & $47(90.4)$ & $48(92.3)$ & \\
\hline Employed & $5(9.6)$ & $1(1.9)$ & $0(0)$ & \\
\hline Retired & $3(5.8)$ & $4(7.7)$ & $4(7.7)$ & \\
\hline Income & & & & $0.639^{c}$ \\
\hline Sufficient & $22(42.3)$ & $21(40.4)$ & $19(36.5)$ & \\
\hline Relatively Adequate & $20(38.5)$ & $19(36.5)$ & 27 (51.9) & \\
\hline Inadequate & $10(19.2)$ & $12(23.1)$ & $6(11.5)$ & \\
\hline
\end{tabular}

\footnotetext{
${ }^{\text {a }}$ Data were presented as mean (standard deviation).

${ }^{b}$ One-way analysis of variance (ANOVA).

${ }^{\mathrm{c}}$ Chi-square test.

${ }^{\mathrm{d}}$ Linear-by-Linear chi-square.

e Fisher exact test.
} 
Table 2. Comparison of Total Score of Depression Before and After Intervention by Study Groups

\begin{tabular}{|c|c|c|c|c|}
\hline Total Score of Depression & $\begin{array}{c}\text { Baseline } \\
\text { Mean }(\text { SD })^{\text {a }}\end{array}$ & $\boldsymbol{P}^{\mathrm{d}}$ & $\begin{array}{c}8 \text { Weeks After Intervention } \\
\text { Mean( SD) }\end{array}$ & $P^{\mathrm{e}}$ \\
\hline Bitter orange $(n=52)$ & $21.38(4.33)$ & & $14.48(4.24)$ & \\
\hline Lavender $(n=52)$ & $20.82(4.30)$ & 0.262 & $14.07(3.41)$ & $<0.001$ \\
\hline Placebo $(n=52)$ & $20.01(4.13)$ & & $16.78(4.16)$ & \\
\hline Comparison of Between the Groups & $\mathrm{MD}(\mathrm{Cl} 95 \%)^{\mathrm{b}}$ & $P$ & Adjust MD (Cl 95\%) ${ }^{c}$ & $P$ \\
\hline Bitter orange with Lavender & $0.55(-1.41$ to 2.53$)$ & 0.783 & 0.12 (1.21 to 1.47$)$ & 0.850 \\
\hline Bitter orange with Placebo & $1.36(-0.61$ to 3.34$)$ & 0.234 & $-2.88(-4.26$ to -1.51$)$ & $<0.001$ \\
\hline Lavender with Placebo & 0.80 (1.16 to 2.78$)$ & 0.599 & $-3.01(-4.40$ to -1.63$)$ & $<0.001$ \\
\hline
\end{tabular}

Number of participants in each group was 52 before and after intervention.

a Mean (standard deviation).

${ }^{\mathrm{b}}$ Mean difference $(95 \% \mathrm{Cl})$.

${ }^{\mathrm{c}}$ Mean difference $(95 \% \mathrm{Cl})$ adjusted for the baseline values and the confounding factors included menopausal age and women age).

${ }^{d}$ One-way analysis of variance (ANOVA) was used for comparison of the baseline scores.

e General linear model for comparison of the follow-up scores.

imipramine alone (24).

In a clinical trial on 80 outpatients referred to psychiatric clinic of Hajar hospital in Sahrekord, Iran, Nikfarjam et al concluded that lavender had positive therapeutic effects in patients with depression and had improved the patients, which is consistent with the findings of the present study. In that study, the control group received $20 \mathrm{mg}$ citalopram tablet with 2 glasses of water and rock candy as a placebo twice daily, while the intervention group, in addition of 20 mg citalopram, received $5 \mathrm{~g}$ of dried lavender shoot twice daily in the form of decoction in the morning and evening with rock candy for 8 weeks (34).

In a study on adult male mice, Mahmoodi et al reported antidepressant effects of bitter orange extract, which is consistent with our findings (37).

Choi et al carried out a double-blind study to evaluate the effect of inhalation of bitter orange essential oil with concentrations of 0.1 and 0.5 on symptoms of menopause and estrogen levels in 63 menopausal women for 5 days and reported that bitter orange essential oil reduced the menopausal symptoms such as depression, insomnia, and stress; however, estrogen levels remained unchanged. Results are consistent with those of the present study (32).

Itai et al conducted a study to determine the effects of inhalation aromatherapy with lavender and Hiba on anxiety and depression of 14 dialysis patients for 6 weeks and showed that Hiba aroma significantly reduced anxiety and

Table 3. The Frequency of Adverse Events by Study Groups

\begin{tabular}{|c|c|c|c|}
\hline Adverse Events & $\begin{array}{c}\text { Bitter Orange } \\
\text { (n = 48) } \\
\text { No. (\%) }\end{array}$ & $\begin{array}{c}\text { Lavender } \\
\text { (n= 49) } \\
\text { No. (\%) }\end{array}$ & $\begin{array}{l}\text { Placebo } \\
\text { (n= 48) } \\
\text { No. (\%) }\end{array}$ \\
\hline Nausea & $2(4.2)$ & $4(8.2)$ & $5(10.4)$ \\
\hline Vomiting & 0 & 0 & 0 \\
\hline Palpitations & $2(4.2)$ & $2(4.1)$ & $1(2.1)$ \\
\hline Headache & $1(2.1)$ & $2(4.1)$ & $3(6.3)$ \\
\hline Others $^{a}$ & $2(4.2)$ & 0 & $4(8.4)$ \\
\hline
\end{tabular}

abdominal pain, bloating, stomach pain. depression in patients, and lavender aroma resulted in a significant decrease only in the anxiety levels, which is inconsistent with the present study (38).

In a double-blind study conducted to determine the effects of inhalation aromatherapy on anxiety and depression of 313 patients treated with radiation, Graham et al reported that lavender aromatherapy did not significantly reduce the anxiety and depression levels (39). The findings are inconsistent with the present study. The inconsistency between our study and these 2 studies may be due to the differences in number of samples, medication dose, and the administration method (in most studies, lavender has been used for aromatherapy).

Our findings showed that lavender and bitter orange impose no serious health risk, and side effects are mild and transient, which is consistent with the findings reported by Mahmoodi et al (37) and Akhondzadeh et al (24).

Effects of lavender can be attributed to its active substances and their effects on a various neurotransmitters involved in depression. The effects of this plant on gamma-amino-butyric acid (GABA) have been proved, and therapeutic effects of this plant can be due to the role and involvement of GABA in the development of mood disorders (40). Linalool content of lavender affects the nor-

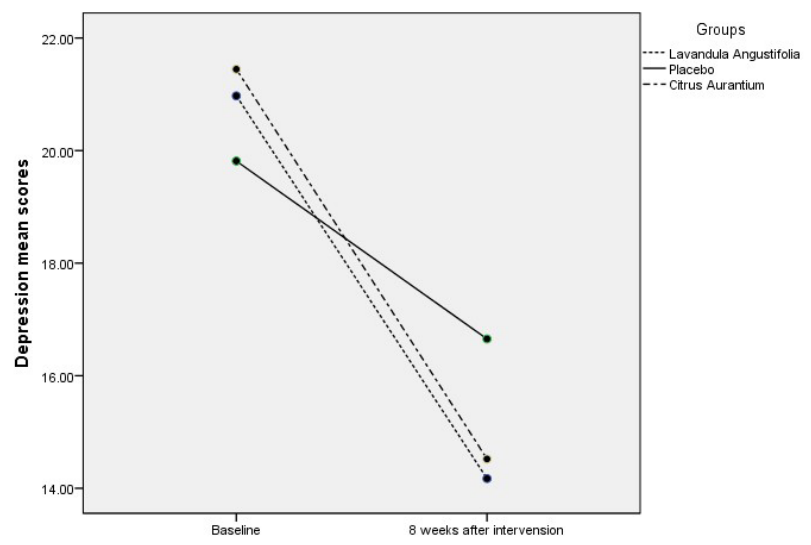

Figure 1. Total Depression Score Among Groups. 
adrenaline and dopamine levels, justifying its antidepressant effects (21). Also, lavender can affect the enzymes, channels and ion receptors leading to brain stimulation, relief anxiety, and anti-depression effects and improve blood flow to the brain (20). Flavonoids found in bitter orange have numerous pharmacological effects including inhibition of oxidation of lipoproteins with low molecular weight, prevention of platelet aggregation and immune cells stabilization; therefore, it is used in the treatment of mental disorders such as depression, allergies and viral infections (41). These seem to justify our findings.

Our study shows that lavender and bitter orange do not have serious risk for health and reported side effects were mild and transient, so we can easily use them in future studies.

A limitation of this study was that participant's responses were considered correct and honest that researcher was not able to verify the responses. The strengths of this study include the random allocation of subjects to avoid selection bias and the use of blinding method to reduce the risk of bias in data collection.

Although many studies have been conducted on depression, few studies have been conducted on the effects of medicinal plants on depression in menopausal women. Therefore, generalization of the results requires further investigations due to the lack of studies in this area.

It is suggested that above medications to be used in men or among other age groups. It is also recommended to consider the effect of other medicinal plants on the depression of postmenopausal women.

\section{Conclusion}

Considering the positive effect of bitter orange and lavender in reducing depression in menopausal women, they can be used as a complementary medicine in depressed patients. However, no statistically significant difference was found between the group receiving bitter orange and lavender 8 weeks after beginning of intervention in terms of depression.

\section{Ethical Issues}

The Research Ethics Committee of Tabriz University of Tabriz Medical Sciences approved the study protocol (code: 1394.98). Also, it was registered at Iranian Registration Clinical Trial website (identifier: IRCT201504236582N11). Written informed consent was obtained from eligible women.

\section{Conflict of Interests}

The authors have no conflict of interest to declare.

\section{Financial Support}

The Research Deputy of Tabriz University of Medical Sciences supported the study.

\section{Acknowledgments}

This article is based on a master's thesis in Department of Midwifery, Faculty of Nursing and Midwifery, Tabriz
University of Medical Sciences. Authors would like to thank the assistance and financial support of the Research Deputy of Tabriz University of Medical Sciences. Authors also appreciate the assistance of authorities and personnel of the clinics of Imam Reza and Fatemiyeh hospitals in West Azerbaijan province, Iran and the cooperation of participants.

\section{References}

1. Khokhar SH. Knowledge, Attitude and Experience of Menopause. Pak J Med Res. 2013;52(2):42-6.

2. Berek JS, Adashy Y, Anderson R, Alvares A, Amesses S, Baker V. Berek and Novak's Gynecology. 14th ed. Philadelphia: Lippinicott Williams and Wilkins; 2012:1116.

3. Gambacciani M, Pepe A. Menopause and related problems. Minerva Med. 2007;98(3):191-201.

4. Allame M, Tohidi M, Selfi P, Alizade A. Menopause. 1st ed. Tehran: Tandis; 2011:70-80. [Persian].

5. Priyadharshini SM, Kalaiselvi VS, Prabhu K, et al. Prediction of age at menopause in women of suburban areas in chennai using a model of fsh over age - a pilot study. Int J Womens Health Reprod Sci. 2014;2(3):214-18. doi:10.15296/ijwhr.2014.30.

6. Pathak KR, Parashar P. Age at menopause and associated bio-social factors of health in Punjabi women. Open Anthropol J. 2010;3:172-80.

7. Rajaeefard A, Beigi MA, Salehi MN. Estimation of natural age of menopause in Iranian women: a meta-analysis study. Koomesh. 2011;13(1):1-7.

8. Hill K. The demography of menopause. Maturitas. 1996;23(2):113-27. doi:10.1016/0378-5122(95)00968-X.

9. Freedman RR. Physiology of hot flashes. Am J Hum Biol. 2001;13(4):453-64. doi: 10.1002/ajhb.1077.

10. Reed DS, Ludman JE, Newton MK, et al. Depressive symptoms and menopausal burden in the midlife. Maturitas. 2009;62(3):306-10. doi: 10.1016/j.maturitas.2009.01.002.

11. Yassary F, Afshary p, Tadayon M, Komeili H, Haghighyzade $\mathrm{MH}$. Frecuency of depression and realated factors in postmenopause women refering to the health center in Dezful. Jundishapur Sci Med J. 2011;6(10):665-674.

12. Hunter SM. Depression and the menopause. BMJ. 1996;313(7067):1217-8.

13. Dwyer VA, Whitten LD, Hawrelak AJ. Herbal medicines, other than St. John's Wort, in the treatment of depression: a systematic review. Altern Med Rev. 2011;16(1):40-9.

14. Taavoni S, Ekbatani NN, Haghani H. The Effect of lemon Balm on sleep disorder in menopausal women $60-50$. Tebe Mokammel Journal. 2012;4:66-76. [Persian].

15. Ortmann $\mathrm{O}$, Lattrich $\mathrm{C}$. The treatment of climacteric symptoms. Dtsch Arztebl Int. 2012;109(17):316-24. doi: 10.3238/arztebl.2012.0316.

16. Donoghue JM, Tylee A. The treatment of depression: prescribing patterns of antidepressants in primary care in the UK. Br J Psychiatry. 1996;168(2):164-8. doi:10.1192/ bjp.168.2.164.

17. Denner SS. Lavandula angustifolia miller: english lavender. Holist Nurs Pract. 2009;23(1):57-64. doi: 10.1097/01. HNP.0000343210.

18. Fibler M, Quante A. A case series on the use of lavendula oil capsules in patients suffering from major depressive disorder and symptoms of psychomotor agitation, insomnia and anxiety. Complement Ther Med. 2013;22:63-9. doi: 
10.1016/j.ctim.2013.11.008.

19. Peana TP, Moretti DM. Linalool in essential plant oils: pharmacological effects. Botanical Medicine in Clinical Practice. 2008;10(55):716-24.

20. Bakhsha F, Mazandarani M, Aryaei M, Jafari Y, Bayate $\mathrm{H}$. Phytochemical and anti-oxidant activity of lavandula angustifolia mill. essential oil on preoperative anxiety in patients undergoing diagnostic curettage. Int J Womens Health Reprod Sci. 2014;2(4):268-71. doi: 10.15296/ ijwhr.2014.42.

21. Yamada K, Mimaki Y, Sashida Y. Effects of inhaling the vapor of Lavandula burnatii super-derived essential oil and linalool on plasma adrenocorticotropic hormone (ACTH), catecholamine and gonadotropin levels in experimental menopausal female rats. Biol Pharm Bull. 2005;28(2):378-9. doi:10.1248/bpb.28.378.

22. Kritsidima M, Newton T, Asimakopoulou K. The effects of lavender scent on dental patient anxiety levels: a cluster randomised-controlled trial. Community Dent Oral Epidemiol. 2010;38(1):83-7. doi: 10.1111/j.16000528.2009.00511.x.

23. Muzzarelli L, Force M, Sebold M. Aromatherapy and reducing preprocedural anxiety: a controlled prospective study. Gastroenterol Nurs. 2006;29(6):466-71.

24. Akhondzadeh SH, Kashani L, Fotouhi A, et al. Comparison of lavandula angustifolia Mill. tincture and imipramine in the treatment of mild to moderate depression: a doubleblind, randomized trial. Prog Neuropsychopharmacol Biol Psychiatry. 2003;27(1):123-7. doi:10.1016/S02785846(02)00342-1.

25. Khan AI, Abourashed AE. Leung's encyclopedia of common natural ingredients: used in food, drugs and cosmetics. 3, editor: John Wiley \& Sons; 2011. 406-10 p.

26. World Health Organization. WHO monographs on selected medicinal plants 2007. http://apps.who.int/medicinedocs/ en/m/abstract/Js14213e/.

27. Masten AS. Bitter orange (citrus aurantium var. amara) extracts and constituents $( \pm)$-p-synephrine and p-octopamine: review of toxicological literature. national toxicology program, national institute of environmental health sciences, national institutes of health, US department of health and human services. Contract. 2004;1:1-73.

28. Bent S, Padula A, Neuhaus J. Safety and efficacy of citrus aurantium for weight loss. Am J Cardiol. 2004;94(10):135961. doi: 10.1016/j.amjcard.2004.07.137.

29. Suryawanshi SJ. An overview of Citrus aurantium used in treatment of various diseases. Afr J Plant Sci. 2011;5(7):3905 .

30. Colker CM, Kaiman DS, Torina GC, Perlis T, Street C.
Effects of Citrus aurantium extract, caffeine, and St. John's wort on body fat loss, lipid levels, and mood states in overweight healthy adults. Curr Ther Res. 1999;60(3):14553. doi:10.1016/S0011-393X(00)88523-9.

31. World Health Organization. WHO Traditional Medicine Strategy. Geneva: WHo; 2013.

32. Choi SY, Kang P, Lee HS, Seol GH. Effects of inhalation of essential oil of Citrus aurantium L. var. amara on menopausal symptoms, stress, and estrogen in postmenopausal women: a randomized controlled trial. Evid Based Complement Alternat Med. 2014;2014:796518. doi: 10.1155/2014/796518.

33. Khanavi M, Mirkarimi M, Karimi M, Sahebalzamin M, Majd AH. Effects of inhalation aromatherapy on female students' anxiety and depression settling in dormitory of Tehran University of Medical Sciences. Medical Science Journal of Islamic Azad Univesity-Tehran Medical Branch. 2010;20(3):175-81. [Persian].

34. Nikfarjam M, Parvin N, Asarzadegan N. The effect of lavandula angustifolia in the treatment of mild to moderate depression. Journal of Shahrekord University of Medical Sciences. 2010;11(4):66 -73. [Persian].

35. R Z, Mohamadi HF, Jalilolghadr S, Alipour HM. investigating the effect of Citrus aurantium aroma on sleep quality of patients hospitalized in the coronary care unit (CCU). Complementary Medicine Journal of Faculty of Nursing \& Midwifery. 2014;4(1):720-33. [Persian].

36. Gharaie B. The study of identity styles in depressed adolescent in thehran Psychiatric Institute. 2004:5(2):42-86.

37. Mahmoodi M, Meimandi SM, Foroumadi A, Raftari SH, Shekari AM. Anti-depressant effect of sour orange flowers extract on Lipopolysaccharide-induced depressive-like behaviors in rat. Journal of Kerman University of Medical Sciences. 2005;12(4):244-51. [Persian].

38. Itai T, Amayasu H, Kuribayashi M, et al. Psychological effects of aromatherapy on chronic hemodialysis patients. Psychiatry Clin Neurosci. 2000;54(4):393-7. doi: 10.1046/j.1440-1819.2000.00727.x.

39. Graham PH, Browne L, Cox H, Graham J. Inhalation aromatherapy during radiotherapy: results of a placebocontrolled double-blind randomized trial. J Clin Oncol. 2003;21(12):2372-6. doi: 10.1200/JCO.2003.10.126.

40. Kaplan HI, Sadock BJ. Synopsis of psychiatry: Behavioral sciences clinical psychiatry. Baltimore, MD: Williams \& Wilkins Co; 2008:80-3.

41. Ames BN. Micronutrients prevent cancer and delay aging. Toxicol Lett. 1998;102:5-18. doi:10.1016/S03784274(98)00269-0.

Copyright ( 2017 The Author (s); This is an open-access article distributed under the terms of the Creative Commons Attribution License (http://creativecommons.org/licenses/by/4.0), which permits unrestricted use, distribution, and reproduction in any medium, provided the original work is properly cited. 